\title{
AHP MODEL FOR PRIMARY SCHOOL TEACHING AND LEARNING ICT APPRAISAL: USER PERCEPTION
}

\author{
Astrid Oddershede*, Francia Farías, Jorge Donoso \\ Industrial Engineering Department \\ Universidad de Santiago de Chile, Chile \\ E-mail: astrid.oddershede@usach.cl \\ Patricia Jarufe \\ Escuela Ingeniería Comercial \\ Universidad Diego Portales, Santiago, Chile \\ E-mail: patricia.jarufe@udp.cl
}

\begin{abstract}
This paper presents a study related to the connotation of Information and Communication Technology (ICT) support at primary school. Through multicriteria approach by the use of the Analytic Hierarchy Process (AHP) a case study involving three types of school at the Metropolitan region in Chile is carried out. Empirical data was collected comprising diverse representatives connected with primary education and with academic experience revealing the existence of multiple and complex criterion. An AHP decision model is developed to find out the attributes priorities and the most important activities that require ICT support generating a starting point to analyze the key factors described as more relevant for teaching and learning at primary school.
\end{abstract}

Keywords: AHP, ICT system, Teaching and Learning, Primary School.

\section{Introduction}

Information and communication technology (ICT) systems have been highly recognized and incorporated to the education process at schools long ago. It has been observed that ICT support the individual learning, stimulate the capacity in learning to learn. However, so far, most studies refer to the transformation of the way of teaching rather than corroborating the improvement of the scholarly results. Perez, Hernando \& Aguaded (2011) evaluate the impact of ICT on educational institutions through interviews and group discussions to reveal the challenges, demands and perceptions of teachers involved in this experience. Peinado, Bolivar \& Briceño (2011) study through a non experimental research with correlational transactional design the attitudes of middle school teacher to the computer revealing that teachers are in advanced stages of technology adoption. Fernandez M., Cebreiro \& Fernandez C. (2010) presents an exploratory analysis of the competence levels in educational network assessed by the own students and by their teachers. In previous work we have explored for university education (Oddershede, Jarufe \& Montalva, 2012). In a similar attempt, the purpose of this study is to investigate the connotation of ICT system support in primary schools in order to contribute with the challenge of improving the teaching and learning process. Provided that, in the field of education take place conflicting aspirations when deciding: what, how and when to apply new technology, a pilot study has been based on the vision of experts to carry out an assessment related to the meaning of ICT support in the process of primary education.

A case study was carried out involving three types of primary schools in Chile. An AHP model is developed to determine the attributes, priorities and the most important activities that require ICT support. The results will give a guide for decision makers (DMs) about ICTs tools requirement and to

\footnotetext{
${ }^{*}$ Corresponding author
} 
train the user/actors for primary education. The next section gives a description of the system in study. Following, in section 3 the application of AHP to design a model is presented. Section 4 delivers the result analysis, where in section 5 the conclusions are provided.

\section{System Description}

With the incorporation of ICT as a support and resource in primary education in Chile arises a question related to the extent to which ICT influences the quality of primary education. In response, this study is carried out to learn about the diverse elements that have contributed to the success or the eventual failure of ICT use, considering different perspectives. However, having in mind that there are many factors that contribute to quality of education, (Tsinidou \& Gerogiannis, 2010; Hanushek \& Rivkin, 2010), for this investigation, six influential factors are considered; the teaching quality determined by the pedagogic practice to achieve an effective learning; the number of students per course that favors an effective learning; the college infrastructure, which allows the innovation for the development of an efficient learning process; the result of the SIMCE test (MINEDUC, 2011; Arrau, 2005) that tests the validity of the current educational model from first to four level in Chile and eight grade; the parents educational and socio-cultural level, which contributes to the motivation and the affectivity of the student; and an ICT system that support the development of the educational process and the performance of students, teachers and administrators. The factors proposed are validated by a group of experts, consisting of specialist teachers, officials of the Ministry of Education and education consultants. Then, in accordance with national government dependence, we have selected three types of primary schools: a city council school with national state financial support; a private school with national state financial support and private school without national state financial support. Furthermore, the actors of the selected schools: students, teachers and administrative staff corroborated the proposed factors since each one uses ICT for their daily duties and responsibilities.

Given that is of interest, to know to what extent experts perceive the importance of the ICT system for the work they currently perform and the type of technology they would require, the initiative to create a decision making model that enables us to identify priority activities and more relevant aspects to be supported by an ICT system with the purpose to contribute to primary school teaching and learning emerges. In this way we might be able to detect where to place efforts to train and improve the competencies in the use of ICT to each establishment and, thus, improve their performance.

\section{Analytic Hierarchy Process Application}

The decision model proposed will be analyzed from the actors' perspective using AHP (Saaty, 1997) methodology. AHP orders, structure the problem in study, formulate a hierarchy and follow a comparison procedure to analyze and prescribe a course of action helping DMs to find the alternative that best meets the needs identified. This approach provides the structure and the mathematics for helping decision-makers make rational decisions.

\subsection{Structuring Process}

The system under study involved three stages. The first stage is concerned with the identification of decisive factors and attributes that actors (students, teachers and administrative staff) consider important for evaluating the ICT provision at primary school operations. However, individually each participant has different expectations about the system and possibly will desire many different characteristics. Empirical data was collected from the selected schools. This practice allowed us to specify the criterion and to structure the problem situation designing a hierarchy structure. Once criteria are determined, the next stage is a prioritization process. A team of experts is comprised with representatives from each of the three types of schools. Then a comparison process is carried out based on experts' judgment and decisive factors to rank the ICT support to primary school related activities. In this way, we will be able to observe if activities that move the organization are developed with the help of technologies. The common activities declared by representatives of the three type of institution considered are depicted in Table 1. 
Table 1.Actors, activities and description

\begin{tabular}{|c|c|c|}
\hline School & Activities & Description \\
\hline \multirow[t]{4}{*}{ Teacher } & Evaluations & Regulation design to grade students \\
\hline & Student Grading \& administrative duties & Grading records \\
\hline & Communication and Provide information & $\begin{array}{l}\text { Transmit and share information, students, } \\
\text { parents, and administrative staff. }\end{array}$ \\
\hline & Lectures & Preparing and teaching lessons \\
\hline \multirow[t]{4}{*}{ Students } & Study and Information search. & Study and search \\
\hline & Homework and tests & Homework and study lessons preparation \\
\hline & Presentations & Design and prepare presentations \\
\hline & Data Exchange, & Data sharing and exchange \\
\hline \multirow[t]{3}{*}{ Administrative staff } & Data transfer & To transfer data \\
\hline & Student Enrollment Control & Students enrollment records \\
\hline & Finance & Financial records. \\
\hline
\end{tabular}

\subsection{ICT system provision}

In previous section, we summarize current typical activities each actor considered. Table 2 gives a summary, of the technological tools used in some of those activities as declared by the actors.

Table 2.ICT systems used by the actors

\begin{tabular}{|l|l|l|}
\hline ICT sVstem & Description & Provision \\
\hline Internet & Web site. & School, home, Cyber Café \\
\hline $\begin{array}{l}\text { Microsoft Office } \\
\text { (PowerPoint, Excel, Word) }\end{array}$ & Office Software & Ministry of Education \\
\hline Private Software & Other prívate software & Private \\
\hline Video and TV & $\begin{array}{l}\text { Information provided by Video \& TV } \\
\text { programs (CNN- History Channel) }\end{array}$ & Television \\
\hline Library on line & On line catalog, electronic collection & $\begin{array}{l}\text { Primary school, Ministry of } \\
\text { Education, City library, }\end{array}$ \\
\hline
\end{tabular}

\subsection{Hierarchy}

A three level hierarchic structure based upon the information specified by the experts was formulated. Figure 1 shows the basic structure where the levels represent as indicated below.

- Level 0 indicates the global objective: ICT system support

- Level 1 indicates the main actors

- Level 2 comprise the main activities the actors al involved

- Level 3 consist of those alternatives ICT support to develop their activities

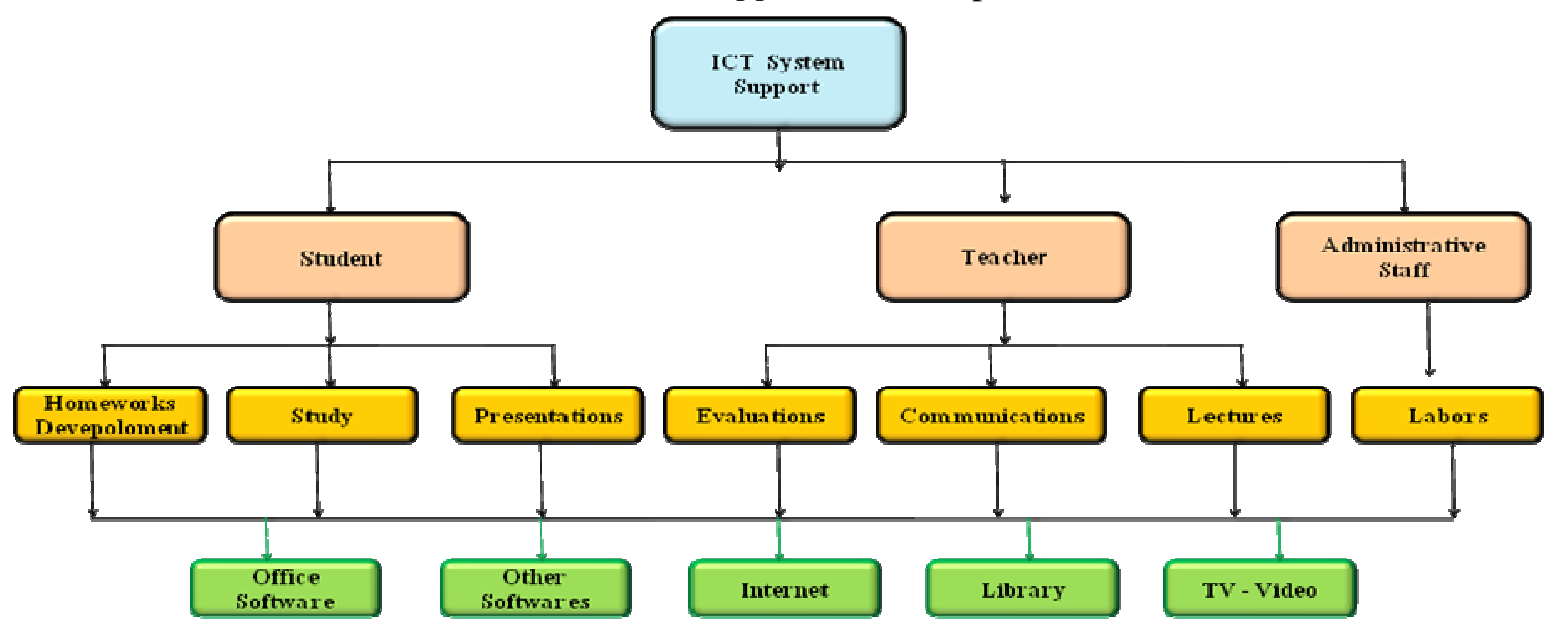

Figure 1.Hierarchical structure for ICT system support in primary education 


\subsection{Experts Panel}

Once the basic structure was stated, the effort was oriented to create (Hurtado, 2003) a Team of Experts. This interdisciplinary Team included thirty experienced people, as described in section 2, related to primary education and the three types of schools in study who emitted judgments to obtain a priority ranking for all the elements of the hierarchy.

\section{Results}

Through Table 3 it is possible to appreciate the overall prioritization results for the actors at level 1 . Table 4 shows the overall priorities for the alternative ICT tools that actors consider essential for developing their daily task.

Table 3.Actors Overall Priority Result

\begin{tabular}{|l|c|}
\hline Actors & Priorities \\
\hline Students & $45,5 \%$ \\
\hline Teacher & $45,5 \%$ \\
\hline Administrative Staff & $9,1 \%$ \\
\hline & \\
\hline & \\
\hline
\end{tabular}

Table 4.Overall Priorities for ICT system

\begin{tabular}{|l|l|}
\hline ICT systems & Priorities \\
\hline Internet & $57,4 \%$ \\
\hline Office software & $16,6 \%$ \\
\hline Library on Line & $13,5 \%$, \\
\hline Other software & $8,4 \%$ \\
\hline TV/Video & $4,0 \%$ \\
\hline
\end{tabular}

Taking into account that this is a global result for the present situation, from tables $3 \& 4$ it is possible to visualize that the support of the computer assisted system (internet, e-mails, web, etc.) have more significance for the students and teachers, with a priority of 57,4\%. Although, when we evaluate schools separately we found some differences. Independently of the type of school the administrative staffs give minimal importance to the ICT in relation to the importance given by the students and teachers.

\subsection{Student's perspective}

Through Figure 2 we can appreciate the relative importance for student activities and in figure 3 the relative importance ICT support for schools to develop activities.

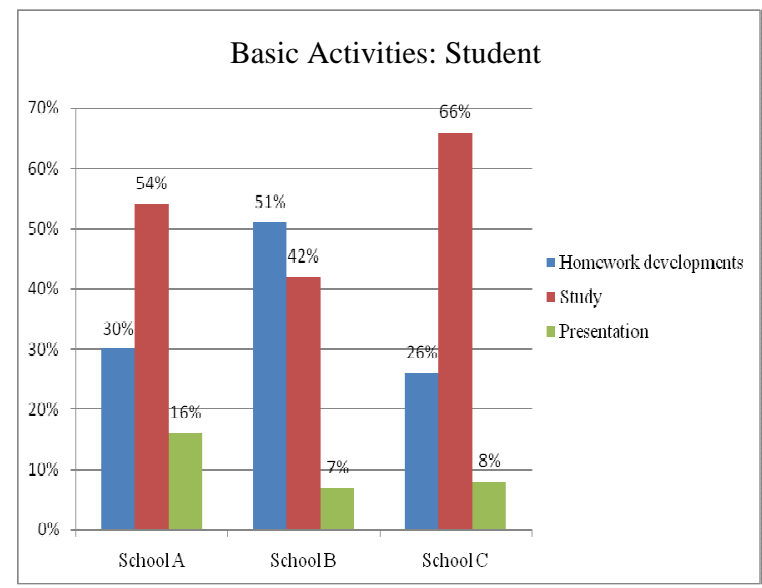

Figure 2.Student activities priority

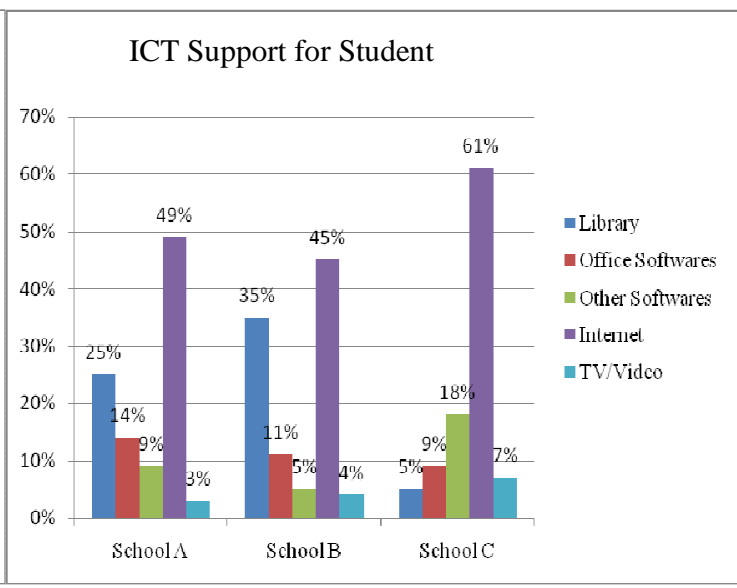

Figure 3.ICT support priority for school type.

Where, School A refers to private school with state financial support, School B represent city council school with state financial support and School C private school without state financial support.

Depending on the type of school, we observe that in the private schools and private state subsidized give greater importance to the ICTs support in the study and preparing lessons, while the municipal schools students give greater importance for developing homework. 


\subsection{Teacher's perspective}

Teachers, depending on the type of college give greater or lesser importance to the ICT, for the activities they perform. In the private schools and in the state subsidized private schools gave the greatest importance of ICT support to the communications, while in the municipal schools gave it to teaching and lectures. In figure 4 we can appreciate the relative importance for teacher activities and in figure 5 the relative importance of ICT support for developing their activities.

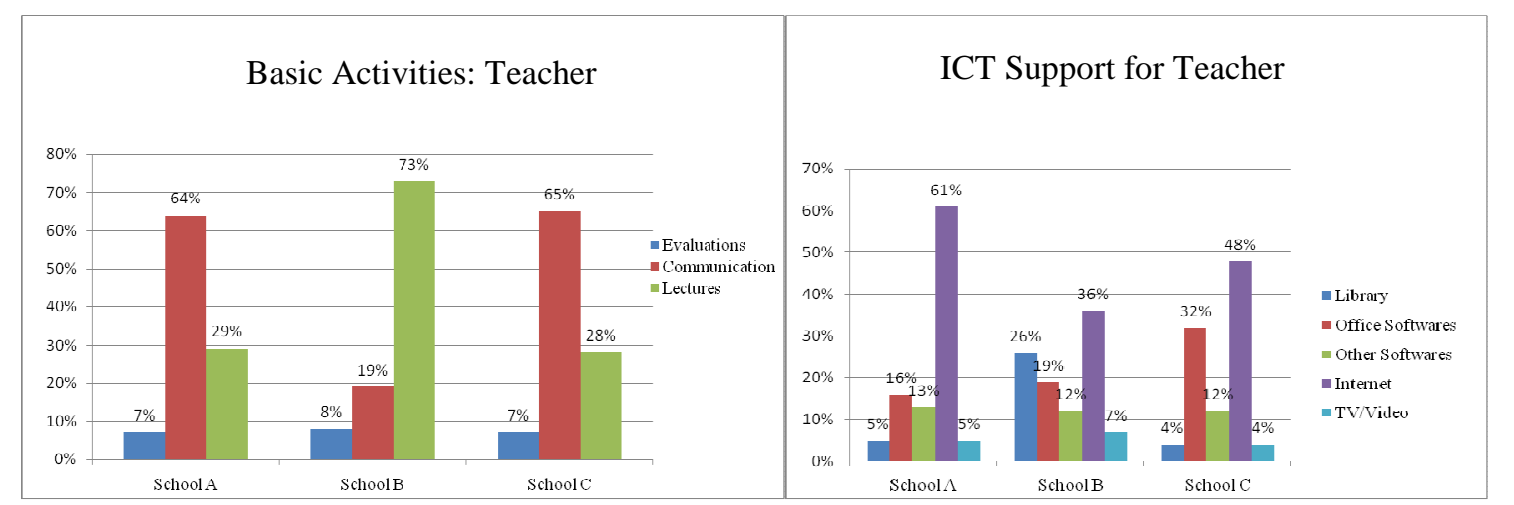

Figure 4.Teacher activity priority

Figure 5.ICT support priority for school type

\subsection{Result analysis}

Concerning to the teaching and learning process in primary education the results indicated that globally ICT support has a greater impact on the students and teachers. Independently on the type of school, the actors identified five ICT tools that are commonly used in primary education; they assign greater importance to Internet and the minor to the TV/Video (figures 4 and 5).

In section 2 we proposed six influential factors that contribute to quality of education. They were evaluated by the expert team delivering the results indicated in figure 6 , indicating that the teacher quality is the most important factor. However, given the results of SIMCE test (figure 7), perception of actors indicated that the ICT support impact in performance of the three types of primary school.

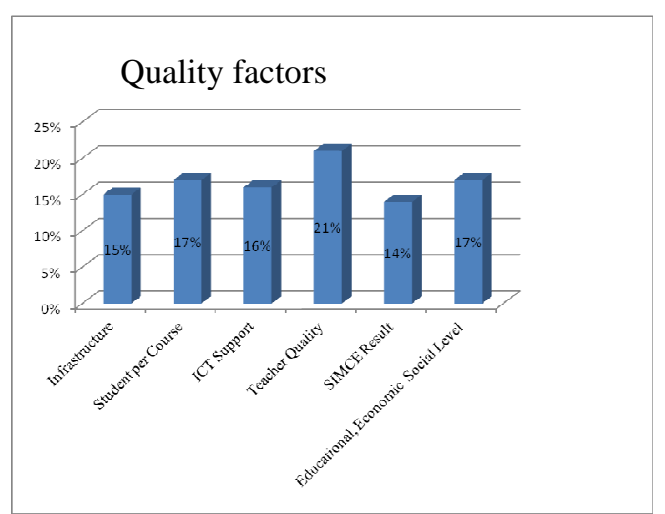

Figure 6.Proposed quality factors in education.

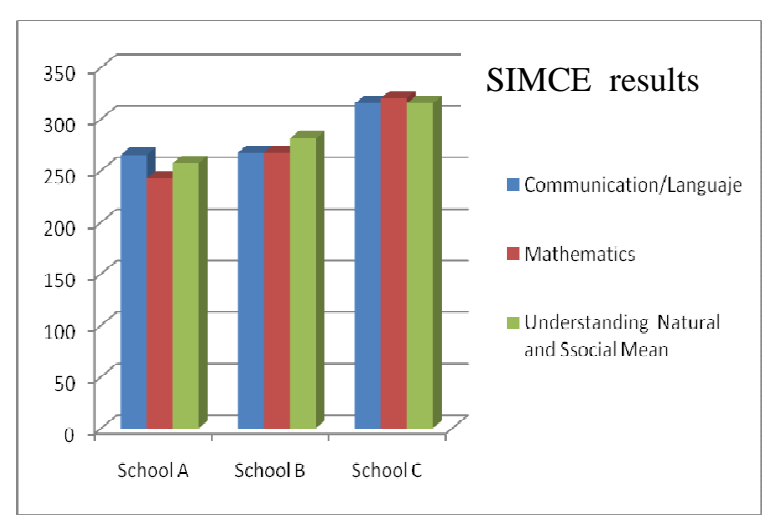

Figure 7.SIMCE results for schools.

According to the performance in the SIMCE test, the private schools (School C) are the ones that present the best scores in SIMCE test, while the municipal schools (School B) obtain the lowest scores and private subsidized schools (School A) an average .

\section{Conclusions}

The application of a scientific decision method, the AHP, was valuable to identify the high-priority dimensions of ICT support in primary education in Chile through a case study. 
The AHP helped the experts to identify advantages and limitations of the ICT support.

The expert team perceived that the outcome of the SIMCE test and the ICT support are crucial factors for the quality of primary education. The investigation revealed that the results of the SIMCE test showed better result for those schools who assigned most importance to the ICT support demonstrating a gap between those schools that assigned lower importance.

However, ICT system is only one of the factors that have an effect in the quality of education, the results of this pilot study generates a opening to analyze the other key factors resultant as more significant for the primary teaching and learning process and to examine the critical aspects that would need to be reworked.

\section{Acknowledgments}

This study was supported by DICYT Project at Universidad de Santiago de Chile.

\section{REFERENCES}

Arrau, C. F. (2005), Indicadores De Calidad De La Educación Básica Y Media En Chile, Biblioteca Del Congreso Nacional De Chile Departamento De Estudios, Extensión y Publicaciones.

Fernandez, M. C., Cebreiro, B., \& Fernandez, C. (2010) Skills for Learning Network of High Students in Galicia. ISSS: 1133-8482 - No 38 Julio- Diciembre 2010, 7 - 21, Pixel-Bit. Revista de Medios y Educación.

Hurtado de Mendoza, F. S. (2003), Como seleccionar los expertos, http://www.monografia.com (15 de noviembre de 2010).

MINEDUC, Sistema de medición de la calidad de la educación: SIMCE, en http://www.simce.cl/ (01 de marzo de 2011).

Tsinidou, M., \& Gerogiannis, V. (2010). Evaluation of the factors that determine quality in higher education: an empirical study. Assurance in Education, 2010, emeraldinsight.com.

Hanushek, E.A., \& Rivkin, S.G. (2010). Generalizations about Using Value-Added Measures of Teacher Quality Paper Presented at the annual meetings of the American Economic Association Atlanta, GA January 3-5, 2010. http://www.usapr.org/paperpdfs/54.pdf 1

Oddershede, A., Jarufe, P., \& Montalva, M. (2012). Evaluación del Uso y Absorción de las TIC's para la Gestión en Educación Superior. Paper presented at XXVIII Encuentro Nacional de Facultades de Administración y Economía. ENEFA, 2012.

Peinado,S., Bolivar, J., \& Briceño, L. ( 2011). Actitud hacia el uso de la computadora en docentes d educación secundaria, CONHISREMI; Revista Universitaria Arbitrada de Investigación y Dialogo Academico,7(1).

Pérez, A., Hernando-Gómez, \& A., Aguaded-Gómez, I. (2011). ICT integration in educational institutions: perceptions of head teachers and coordinators, Estudios Pedagógicos XXXVII, 2, 197211.

Saaty, T.L. (2008). Decision making with the analytic hierarchy process. Int. J. Services Sciences, $1(1)$. 